\title{
Hypothalamic-Pituitary-Adrenal Axis Function in Chronic Fatigue Syndrome
}

\author{
Filip Van Den Eede ${ }^{a, c, d} \quad$ Greta Moorkens $^{b}$ Boudewijn Van Houdenhove ${ }^{e}$ \\ Paul Cosyns ${ }^{a, c}$ Stephan J. Claes ${ }^{d, e}$ \\ Departments of a Psychiatry and ${ }^{b}$ Internal Medicine, University Hospital Antwerp, Edegem, \\ ${ }^{c}$ Collaborative Antwerp Psychiatric Research Institute, University of Antwerp, ${ }^{d}$ Department of \\ Molecular Genetics VIB8, Flanders Interuniversity Institute for Biotechnology, University of Antwerp, \\ Antwerp, and 'Department of Psychiatry, University Hospital Gasthuisberg, Leuven, Belgium
}

\section{Key Words \\ Challenge test $\cdot$ Cortisol $\cdot$ Corticotropin-releasing factor . Fatigue $\cdot$ Neuroendocrinology $\cdot$ Stress}

\begin{abstract}
There is evidence for a hypofunction of the hypothalamicpituitary-adrenal (HPA) axis in a proportion of the patients with chronic fatigue syndrome (CFS), despite the negative studies and methodological difficulties. In this review, we focus on challenge studies and on the role of the HPA axis in the pathogenesis of CFS. Mild hypocortisolism, blunted adrenocorticotropin response to stressors and enhanced negative feedback sensitivity to glucocorticoids are the main findings. Several underlying mechanisms have been proposed. Currently, it is a matter of debate whether these disturbances have a primary role in the pathogenesis of CFS. However, even if the HPA axis dysfunctions are secondary to other factors, they are probably a relevant factor in symptom propagation in CFS.

Copyright $\odot 2007$ S. Karger AG, Basel
\end{abstract}

\section{Introduction}

Chronic fatigue syndrome (CFS) is characterized by unexplained, profound disabling and long-lasting fatigue that is of new or definite onset, that is not the result of ongoing exertion and that is not substantially alleviated by rest. The fatigue must be accompanied by at least 4 or more of the following case-defining symptoms during at least 6 months of consecutive illness: sore throat, tender cervical or axillary lymph nodes, muscle pain, multijoint pain, postexertional malaise, unrefreshing sleep, headaches and impaired memory or concentration [1]. The suggestion that CFS may be related to a dysfunction of the hypothalamic-pituitary-adrenal (HPA) axis derives from clinical similarities between CFS and states of glucocorticoid deficiencies [2], as well as from early observations of reduced adrenocortical activity in chronically fatigued patients [3]. Furthermore, there is evidence for an involvement of physical and psychological stress in vulnerability, onset and/or perpetuation of CFS [4-11]. In the past, stress has generally been associated with HPA axis hyperactivity, resulting in hypercortisolism. However, chronic stress can also lead to HPA axis hypoactivity, as is the case in several stress-related disorders [12-14]. In

Filip Van Den Eede, $\mathrm{PhD}$

Department of Psychiatry, University Hospital Antwerp (UZA)

Wilrijkstraat 10

BE-2650 Edegem (Belgium)

Tel. +32 382149 11, Fax +32 3825 16 41, E-Mail filip.van.den.eede@uza.be 
this review, we will mainly focus on HPA axis-related challenge studies and on possible pathophysiological mechanisms in CFS.

\section{HPA Axis Disturbances in CFS}

\section{Basal Hormonal Changes}

Studies on basal plasma cortisol (single or serial measures), free salivary cortisol and urinary free cortisol have been reviewed extensively by Parker et al. [15] and by Cleare [2]. In summary, in about half of the investigations there was evidence for lowered cortisol levels in CFS. There is only 1 report of elevated salivary cortisol levels in CFS [16]. In all the other studies, no differences were found between CFS patients and control individuals. More recently, the study by Jerjes et al. [17] provided further evidence for reduced basal HPA axis function in CFS. The group of 15 CFS patients without psychiatric comorbidity showed lower urinary free cortisol and corticosterone concentrations than the group of 20 healthy control individuals, whereas diurnal rhythm was normal in CFS patients. Furthermore, Roberts et al. [18] reported a lower salivary cortisol response to awakening in 56 CFS patients compared with 35 control individuals. In contrast, Di Giorgio et al. [19] found no abnormalities in the levels of plasma cortisol in a sample of 15 CFS patients, although they reported reduced levels of adrenocorticotropic hormone (ACTH) over a full circadian cycle and during the physiological morning peak. Finally, regarding basal hormone concentrations in CSF, Demitrack et al. [20] measured cerebrospinal fluid levels of corticotropin-releasing factor (CRF) and ACTH in 19 CFS patients and 26 control individuals, but no differences were apparent. The authors considered this finding to be inappropriately normal' in CFS, given the reduction in glucocorticoid secretion in the periphery (and thus reduced negative feedback) $[20,21]$.

\section{Challenge Tests}

Hypothalamic and Pituitary Function

Table 1 presents an overview of HPA axis-related challenge tests that have been undertaken in CFS. The insulin tolerance test (ITT) is a standardized method for assessing the entire HPA axis [22]. To the best of our knowledge, only 1 study demonstrated reduced ACTH responses in the ITT in CFS [23]. In 2 relatively large studies [24, 25] and 1 small study [26], there were no significant differences in ACTH responses in the ITT between CFS patients and healthy control individuals. These data do not provide strong evidence for a disturbed HPA axis regulation in CFS, although the ITT may be too blunt to be useful in detecting more subtle changes [2]. Demitrack et al. [20] and Scott et al. [27] reported significantly lower ACTH responses after CRF in CFS patients in comparison with healthy individuals, whereas two other research groups did not find any differences in the CRF challenge $[24,28]$. In addition, Altemus et al. [29] argued that the ACTH response to arginine vasopressin (AVP) acts as an indirect index of hypothalamic CRF levels. They found a trend towards a reduced ACTH response to AVP in CFS, which they attributed to a lower ambient level of hypothalamic CRF. Alternatively, Scott et al. [30] hypothesized that a deficit in endogenous AVP could contribute to the attenuated ACTH response in the CRF test. Using desmopressin (DDAVP), an AVP analog, they found that coadministration of DDAVP with CRF normalized the blunted ACTH response to CRF. Consequently, they suggested that CFS may be associated with AVP deficiency and upregulated AVP receptors on the pituitary. Furthermore, blunted ACTH responses to other stressors have been reported in CFS: naloxone [31], exercise and social stress [23]. Finally, in the study by Gaab et al. [32], patients with CFS showed an enhanced and prolonged suppression of salivary free cortisol after the administration of a low-dose of dexamethasone $(0.5 \mathrm{mg})$, pointing to enhanced sensitivity to the negative feedback of glucocorticoids at the pituitary level. In accordance with these findings, we observed lower salivary free cortisol responses in the combined low-dose dexamethasone/CRF test in CFS patients than in control individuals [Van Den Eede, et al., unpubl. data].

\section{Adrenal Function}

In the above-mentioned investigations, an inconsistency can be observed in the relationship between ACTH and cortisol responses in challenge tests. More specifically, a reduced ACTH response in CFS patients has been associated with: (1) lower cortisol responses [27] (but without any correlation between the two variables); (2) no difference in cortisol responses [20, 23, 31]; (3) higher salivary cortisol [23] (table 1). In order to clarify this issue and to examine adrenal function in CFS, several ACTH challenge studies have been performed. In 2 studies with $1 \mu \mathrm{g}$ of ACTH or more, there were no differences in cortisol responses between CFS patients and healthy individuals $[33,34]$, suggesting that adrenal insufficiency is unlikely to play a significant role in CFS. In contrast, Scott et al. [35] and Demitrack et al. [20] reported reduced cortisol responses in the ACTH test. The findings of chal- 
Table 1. Overview of HPA axis-related challenge tests in CFS

\begin{tabular}{|c|c|c|c|c|c|c|c|}
\hline Author & Subjects & $\begin{array}{l}\text { CFS } \\
\text { duration } \\
\text { years }\end{array}$ & MDD & Challenge & $\begin{array}{l}\text { Time of } \\
\text { testing }\end{array}$ & $\mathrm{ACTH}^{1}$ & Cortisol $^{1}$ \\
\hline \multirow[t]{3}{*}{$\begin{array}{l}\text { Demitrack } \\
\text { et al. [20] }\end{array}$} & $\begin{array}{l}19 \mathrm{CFS} \\
18 \mathrm{CON}\end{array}$ & \multirow{3}{*}{$\begin{array}{l}7.2 \\
(\mathrm{n}=30) \\
7.2 \\
(\mathrm{n}=30)\end{array}$} & $3^{2}$ & oCRF $(1 \mu \mathrm{g} / \mathrm{kg})$ & 8 p.m. & lower (net) & no difference (plasma) \\
\hline & $\begin{array}{l}12 \mathrm{CFS} \\
10 \mathrm{CON}\end{array}$ & & \multirow[t]{2}{*}{$?$} & ACTH $(0.003,0.01 \mu \mathrm{g} / \mathrm{kg})$ & 6 p.m. & - & higher (net, plasma) \\
\hline & & & & ACTH $(0.1,1 \mu \mathrm{g} / \mathrm{kg})$ & 6 p.m. & - & lower (net, plasma) \\
\hline \multirow{2}{*}{$\begin{array}{l}\text { Scott } \\
\text { et al. [27] }\end{array}$} & 14 CFS & \multirow{2}{*}{4.8} & \multirow{2}{*}{ none } & \multirow{2}{*}{ oCRF $(100 \mu g)$} & \multirow{2}{*}{1 p.m. } & \multirow{2}{*}{ lower (net) } & \multirow{2}{*}{ lower (net, plasma) } \\
\hline & $14 \mathrm{CON}$ & & & & & & \\
\hline \multirow{2}{*}{$\begin{array}{l}\text { Scott } \\
\text { et al. [31] }\end{array}$} & $13 \mathrm{CFS}$ & \multirow[t]{2}{*}{4.8} & \multirow[t]{2}{*}{ none } & \multirow[t]{2}{*}{ naloxone $(125 \mu \mathrm{g} / \mathrm{kg})$} & \multirow[t]{2}{*}{1 p.m. } & \multirow{2}{*}{$\begin{array}{l}\text { lower peak ACTH } \\
\text { and AUC (net?) }\end{array}$} & no difference (plasma) \\
\hline & $13 \mathrm{CON}$ & & & & & & \\
\hline Scott & $13 \mathrm{CFS}$ & 5.0 & none & oCRF $(100 \mu \mathrm{g})$ & 1 p.m. & lower (net) & lower (net, plasma) \\
\hline et al. [30] & $13 \mathrm{CON}$ & & & 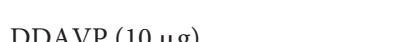 & $1 \mathrm{~nm}$ & no difference & no difference (nlasma) \\
\hline & & & & DDTV (10 pg) & 1 p.111. & 100 amserence & no anterence (prasma) \\
\hline & & & & $\operatorname{DDAVP}(10 \mu \mathrm{g})+\mathrm{oCRF}(100 \mu \mathrm{g})$ & 1 p.m. & no difference & no difference (plasma) \\
\hline Altemus & 19 CFS & 3.7 & none & $\operatorname{AVP}(1 \mathrm{mIU} / \mathrm{kg} / \mathrm{min}, 1 \mathrm{~h})$ & 9.30 a.m. & interaction disorder and & interaction disorder and \\
\hline et al. [29] & $19 \mathrm{CON}$ & & & & & $\begin{array}{l}\text { ACTH; trend towards } \\
\text { reduced peak value }\end{array}$ & cortisol (plasma) \\
\hline Inder & 12 CFS & ? & none & oCRF $(1 \mu \mathrm{g} / \mathrm{kg})$ & 10 a.m. & no difference & no difference (plasma) \\
\hline et al. [28] & $11 \mathrm{CON}$ & & & & & & \\
\hline & & & & naloxone (125 $\mu \mathrm{g} / \mathrm{kg})$ & 10 a.m. & no difference & no difference (plasma) \\
\hline Cleare & 37 CFS & $?$ & none & hCRF (1 $\mu \mathrm{g} / \mathrm{kg})$ & 9 a.m. & no difference & cortisol lower (net, plasma; \\
\hline et al. [24] & $28 \mathrm{CON}$ & & & & & & with ACTH as covariate) \\
\hline & & & & ITT (0.15 U/kg) & 9 a.m. & no difference & no difference (plasma) \\
\hline Bearn & 9 CFS & 5.4 & none & ITT $(0.15$ or $0.1 \mathrm{U} / \mathrm{kg})$ & 10 a.m. & no difference & no difference (plasma) \\
\hline et al. [26] & $10 \mathrm{CON}$ & & & & & & \\
\hline Moorkens & 73 CFS & 1.5 & none & ITT (0.15 U/kg) & variable & no difference & no difference (plasma) \\
\hline et al. [25] & $21 \mathrm{CON}$ & & & & & & \\
\hline Gaab & $21 \mathrm{CFS}$ & 5.6 & 1 & ITT (0.15 U/kg) & 9 a.m. & lower (net and total) & higher cortisol (net, salivary; \\
\hline et al. & $20 \mathrm{CON}$ & & & & & & group by time effect) \\
\hline$[23,32]$ & & & & TSST & 9-10 a.m. & lower (total) & no difference \\
\hline & & & & Cycle test & 14 p.m. & lower (total) & no difference \\
\hline & & & & & & & (plasma or salivary) \\
\hline & & & & DST (0.5 mg) & & - & hypersuppression (salivary) \\
\hline & & & & awakening & awakening & - & no difference (salivary) \\
\hline Van Den & 34 CFS & 2.7 & none & $\operatorname{DEX}(0.5 \mathrm{mg})+\mathrm{hCRF}(100 \mu \mathrm{g})$ & 15 p.m. & - & lower cortisol \\
\hline $\begin{array}{l}\text { Eede et al. } \\
\text { [unpubl.] }\end{array}$ & $25 \mathrm{CON}$ & & & & $(\mathrm{CRF})$ & & $(\text { total, salivary })^{3}$ \\
\hline Scott & $20 \mathrm{CFS}$ & $?$ & 3 & ACTH $(1 \mu \mathrm{g})$ & 2 p.m. & - & lower peak cortisol \\
\hline et al. [35] & $20 \mathrm{CON}$ & & & & & & (net, plasma) \\
\hline Hudson & $20 \mathrm{CFS}$ & $?$ & none & АCTH $(1 \mu \mathrm{g})$ & 12 a.m. & - & no difference (plasma) \\
\hline et al. [34] & $20 \mathrm{CON}$ & & & & & & \\
\hline Gaab & 18 CFS & 5.6 & 1 & ACTH $(1.25 \mu \mathrm{g})$ & 2 p.m. & - & no difference \\
\hline et al. [32] & $18 \mathrm{CON}$ & & & & & & (plasma or salivary) \\
\hline & & & & АCTH $(225 \mu \mathrm{g})$ & 3 p.m.? & - & $\begin{array}{l}\text { no difference } \\
\text { (plasma or salivary) }\end{array}$ \\
\hline
\end{tabular}

CON = Control individual; DST = dexamethasone suppression test; hCRF or oCRF = human or ovine corticotropin-releasing factor; ITT = insulin tolerance test; MDD = major depressive disorder (current); TSST = Trier Social Stress Test.

${ }^{1}$ Results in CFS patients compared to control individuals; 'net' refers to the absolute increase of the hormone (corrected for basal value). ${ }^{2}$ Score on Hamilton Depression Scale $>16 .{ }^{3}$ Net salivary cortisol responses lower in patients, but not statistically significant.

Van Den Eede/Moorkens/ Van Houdenhove/Cosyns/Claes 


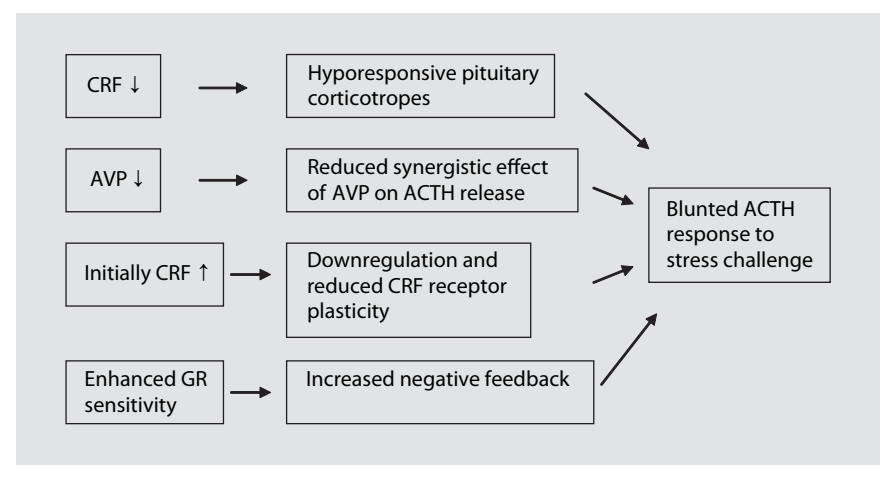

Fig. 1. Proposed mechanisms for blunted ACTH response in challenge tests. GR = Glucocorticoid receptor.

lenge studies taken into account, both research groups interpreted these results as a diminished adrenocortical reserve in CFS, secondary to a reduced stimulation from pituitary ACTH. Interestingly, Scott et al. [36] demonstrated that an abnormal ACTH test (8 out of 32 CFS patients) was associated with reduced adrenal gland size on CT scan. Furthermore, Demitrack et al. [20] found that low doses of ACTH $(0.003 \mu \mathrm{g} / \mathrm{kg}$ or $0.01 \mu \mathrm{g} / \mathrm{kg})$ were associated with higher cortisol responses, suggesting hypersensitivity of the adrenal gland in CFS. Taken together, the adrenal gland may be hypersensitive to low doses of ACTH due to hypocortisolism and there may be a diminished adrenocortical reserve in CFS, secondary to a reduced stimulation from pituitary $\mathrm{ACTH}$.

\section{Confounding Factors}

Methodological difficulties in HPA axis-related research in CFS have extensively been discussed by Cleare $[2,37]$. Therefore, we will only briefly mention some issues that are in the interpretation of the challenge tests. Although the presence of major depression has been mentioned in most of the challenge studies as a possible confounder (HPA axis hyperactivity [38]) (table 1), there are other comorbid conditions that may have an influence on HPA axis function in CFS and that have not been reported systematically in most of the articles. For instance, CFS has been associated with a higher prevalence of early-life stress (ELS; sexual, physical and emotional maltreatment during childhood) $[6,10]$. ELS is characterized by a central hyperactivity of the CRF system [39], which is in contrast with the proposed CRF hypoactivity in CFS. As a consequence, it may be that CFS patients with a history of ELS constitute a subgroup with a different neuroendocrine function. In support of this, CFS patients without a history of ELS showed significantly lower cortisol re- sponses than CFS patients with ELS and control individuals in the combined low-dose DEX/CRF test [Van Den Eede et al., unpubl. data]. Discrepancies have also been found in fibromyalgia, a condition that is related to CFS [40]. Several studies in patients with fibromyalgia resulted in exaggerated ACTH responses in challenge tests, inversely to the findings in CFS [41-44]. While HPA axis physiology may be altered in both fibromyalgia and CFS, the specific changes may be different. Furthermore, the length of illness may be a confounding factor. In the study by Demitrack et al. [20], patients with particularly long length of illness were included, compared with the study by Moorkens et al. [25] (table 1). As to this, Gaab et al. [45] found a significant negative correlation between the ACTH response in the ITT and both the length of illness and the severity of fatigue symptomatology. There may also be an influence of the day time of testing. The 2 CRF challenge studies resulting in reduced ACTH responses in CFS were performed in the afternoon or in the evening $[20,27]$, whereas the 2 negative studies were conducted in the morning [24, 28] (table 1). Finally, other factors such as menstrual status and oral contraceptives may have an influence on HPA axis function [46].

\section{Pathogenesis}

\section{Mechanisms}

Globally, about half of the above-mentioned basal hormone and challenge studies indicated a hypofunction of the HPA axis, whereas no significant differences in HPA axis function between CFS patients and control individuals were apparent in the other studies. The following mechanisms underlying hypocortisolism have been proposed $[12,14]$ :

- Reduced biosynthesis of releasing factors (CRF, AVP, ACTH) or cortisol.

- Hypersecretion of a secretagogue with subsequent downregulation of the target receptors.

- Increased negative feedback sensitivity to glucocorticoids.

- Decreased availability of free cortisol.

- Reduced effects of cortisol on the target tissue (relative cortisol resistance).

Several of these mechanisms may underlie the blunted ACTH responses to stressors and may be involved in the pathogenesis of CFS (fig. 1). There may be a defect at or above the level of the hypothalamus, resulting in a deficiency in the release of CRF and/or other secretagogues that serve to activate the pituitary. In turn, this chronic 
hypodrive may lead to hyporesponsive pituitary corticotropes $[20,21]$. On the basis of their findings in the DDAVP challenge, Scott et al. [30] suggested that a deficit in endogenous AVP may contribute to the attenuated ACTH response in the CRF test, rather than a deficit in central CRF (see also 'Challenge Tests'). Alternatively, the same authors hypothesized that desensitization of the CRF receptors on the anterior pituitary corticotropes may underlie the blunted ACTH response after CRF. According to this theory, an elevation of CRF in the initial stress period produces a downregulation of the CRF receptor that fails to normalize following a reduction in CRF levels. This failure could be due to an abnormality in CRF receptor plasticity [27]. However, a receptor downregulation is difficult to reconcile with the above-mentioned CRF hypodrive and to the best of our knowledge, an abnormality in CRF receptor plasticity has not been reported in CFS. Furthermore, there is evidence for enhanced sensitivity to the negative feedback of glucocorticoids in CFS as the main mechanism underlying hypocortisolism in CFS [32]. Further support for enhanced sensitivity for glucocorticoids in CFS comes from in vitro studies, showing that lower concentrations of DEX were needed to inhibit interleukin production and proliferation of peripheral blood mononuclear cells from subjects with CFS [47-50]. The permanently enhanced negative feedback may lead to an increased central inhibitory tone, resulting in reduced hypothalamic CRF expression [32]. Increased negative feedback at the pituitary level may partly account for the blunted ACTH responses in the challenge tests, although the fact that basal cortisol levels were not shown to confound the ACTH responses in the study by Scott et al. [27] argues against this explanation.

It has to be remarked that disturbances at different levels of the HPA axis in stress-related pathology do not always match with each other in a sense of a global hypoor hyperfunction of the stress system, as proposed by Chrousos and Gold [51]. In posttraumatic stress disorder (PTSD) for instance, a central CRF hyperactivity has been reported, together with (paradoxically) reduced cortisol output and enhanced glucocorticoid negative feedback $[52,53]$. Thus, hypocortisolism does not necessary imply a global HPA axis hypofunction, and further research on the central CRF system in CFS is required. In analogy with PTSD, ELS has been associated with central HPA axis hyperactivity in animal and human studies [39]. However, studies on the disturbances of the glucocorticoid feedback mechanism in ELS in human have been less conclusive. Rinne et al. [54] demonstrated that ELS was associated with an enhanced ACTH and cortisol response in the combined high-dose DEX/CRF test in women with borderline personality disorder and ELS compared to a control group without ELS, pointing to an enhanced central CRF drive and/or a reduced glucocorticoid negative feedback in ELS. In contrast, there have also been reports of an enhanced glucocorticoid negative feedback in patients who experienced ELS $[55,56]$. However, in both studies, patients with ELS showed a high comorbidity of current PTSD (94 and 68\%, respectively), a syndrome that has been associated with enhanced glucocorticoid negative feedback [53]. Further research on the neuroendocrine correlates of ELS and on its role in CFS is required.

\section{Role of the HPA Axis in the Pathogenesis of CFS}

From a pathophysiological point of view, it is tempting to consider a primary role for the observed HPA axis hypofunction in the pathogenesis of CFS. There are indications that physical or psychological stress is a predisposing and/or precipitating factor in CFS [4-11]. The CRF system is a major component of the stress system, and the HPA axis constitutes its peripheral effector [51]. Chronic stress has been associated with HPA axis hypofunction [12-14]. Moreover, CRF is itself a behaviorally active neuropeptide, next to its key role in the regulation of metabolic, neuron-endocrine and autonomic adaptations to stress [57]. Central administration of CRF to animals has been demonstrated to induce signs of physiological and behavioral activation $[58,59]$. There is also evidence that $\mathrm{CRF}$ is involved in the regulation of spontaneous waking as an excitatory peptide [60] and that CRF has analgesic properties [61]. Consequently, the reduction in the availability of central nervous system CRF may contribute to the lethargy and to the pain symptoms in CFS, in addition to its role in the reduced HPA axis output [20].

Neuroendocrine factors such as CRF and growth hormone-releasing hormone have a profound influence on sleep regulation [62]. In major depression for instance, evidence points to a causal relationship between CRF hyperactivity and polysomnographic disturbances [62]. More precisely, intracerebrovascular injection of CRF decreases slow-wave sleep in animals, and there is evidence that CRF promotes REM sleep. A decrease in non-REM sleep (decrease of stage 2 sleep and slow-wave sleep) and REM disinhibition (shortened REM latency, prolonged first REM period and elevated REM density) are polysomnographic characteristics of major depression [62]. In CFS however, studies have not identified characteristic polysomnographic disturbances [4]. In a recent general population-based study by Reeves et al. [63], there were 
no significant differences in rates of primary sleep disorders between CFS patients and nonfatigued control individuals, and there were no differences in sleep architecture either (with the exception of a higher mean frequency of obstructive apnea per hour of night-time sleep in the CFS group, which was not clinically meaningful).

Furthermore, there is a possible link between the HPA axis and immune disturbances in CFS. More precisely, inflammatory mediators such as interleukin-1 recruit the hypothalamic CRF containing neurons in a negative feedback loop in which glucocorticoids exert immunosuppressive effects to prevent the immune response from overshooting. If hypothalamic neurons fail to response adequately to cytokine stimulation, the resultant failure of adequate glucocorticoid-mediated restraint of the immune system results in a hyper-immune state $[13,64]$. According to Dantzer [65], proinflammatory cytokines produced by cells of the innate immune system act on the central nervous system via afferent and humoral pathways to trigger a brain cytokine system that organizes the sickness response in its subjective, behavioral and metabolic components. Finally, other neurobiological pathways may also be involved primarily or secondarily in the HPA axis dysfunction. Serotonergic, noradrenergic and dopaminergic input acts to stimulate the HPA axis. Studies measuring cortisol and prolactin responses to serotonin agonists have provided evidence for a disturbed relationship between the serotonergic system and the HPA axis in CFS [15].

Currently however, it is a matter of debate whether the HPA axis disturbances have a primary role in the pathogenesis of CFS. In his critical review, Cleare [37] states that there is no specific change to the HPA axis in CFS and that the observed disturbances are of multifactorial etiology, with some influencing factors (such as profound inactivity or sleep disturbances) occurring as consequence of the illness. According to this author, the HPA axis is probably not an important factor in the early stages of the fatigue genesis. Instead, HPA axis changes may develop somehow later in the natural history of the disorder. Supporting this notion, the level of HPA axis dysfunction in CFS has been found to be correlated to the length of illness [45]. Furthermore, two prospective investigations demonstrated that becoming fatigued during the first 6 months after an acute precipitant was not linked to hypoactivity of the HPA axis [66, 67]. However, in contrast with these studies, Glass et al. [68] found that amongst regularly exercising individuals, some develop fatigue, musculoskeletal pain and mood changes after a brief period of exercise cessation, while other remained asymptomatic; the symptomatic subjects were characterized by lower HPA axis, auto- nomic and immune function. The authors speculated that a subset of healthy individuals who have a hypoactive function of the biological stress response systems (unknowingly) exercise regularly to augment the function of these systems and to suppress symptoms. These individuals may be at risk for developing 'chronic multisymptom illnesses' when a stressor leads to lifestyle changes that disrupt regular exercise. It has been proposed that after a period of chronic stress and associated 'allostatic load' [70] the stress system may switch from hyper- to hyporesponsiveness via changes in autoregulatory feedback mechanisms, resulting in a typical fatigue/pain/low mood symptom cluster $[12,69]$. This dynamic view on the HPA axis in stress-related disorders is supported by the investigations from Houshyar et al. [71] in rats, demonstrating that enhanced HPA axis responses and decreased sensitivity to negative feedback of glucocorticoids may alter into reduced HPA axis responses and increased negative feedback sensitivity after chronic stress. Large longitudinal studies in humans are necessary to examine how HPA axis disturbances evolve in time and to determine if they precede the development of stress-related disorders, although such studies are difficult to perform because only a small percentage of individuals who are exposed to any stressor will develop symptoms [68]. In addition, genetic studies in humans are required to examine if polymorphisms in HPA axis-related target genes are associated with CFS, in analogy with research in affective disorders $[38,72-75]$. According the study by Goertzel et al. [76], three major candidate genes in CFS are tryptophan hydroxylase, catechol-O-methyltransferase and glucocorticoid receptor. This study has been criticized because of the small number of gene variants that have been investigated and because of the limited number of CFS patients that were included [77]. Recently however, Rajeevan et al. [78] observed an association of multiple single nucleotide polymorphisms in the glucocorticoid receptor gene (NR3C1, gene ID: 2908) with chronic fatigue (patients: $n=95$; controls: $n=42$ ).

When considering the role of the HPA axis in the pathogenesis of CFS, it is important to mention that hypocortisolism is not a specific finding in CFS; it has been observed in several stress-related and bodily disorders [14]. Halbreich [79] has proposed the following possibilities for the interpretation of nonspecific neuron-endocrine abnormalities:

- Endocrine abnormalities may be more specific to clusters of symptoms.

- Endocrine abnormalities represent a generalized nonspecific imbalance (due to stress) and actual symp- 
toms depend on other variables (location of defect, genetics, low threshold in particular system, ...).

- Endocrine abnormalities represent a disturbance in a specific central nervous system region (e.g. limbic system); any pathology that involves that region will be associated with the endocrine abnormalities.

- The current diagnostic system is engraved in stone; endocrine abnormalities are of no diagnostic value.

As to the link between hypocortisolism and symptomatology, treatment trials have provided modest evidence that some patients experience an alleviation of symptoms when hypocortisolism is reversed (see the section below). Given the link in conditions such as Addison's disease between low cortisol and symptoms similar to those seen in CFS [80], it might be argued that, even if HPA axis disturbances are secondary to other factors, low levels of cortisol in CFS could be a factor relevant in symptom propagation and perpetuation [37].

\section{Hydrocortisone Replacement Therapy}

There have been three randomized controlled trials testing the hypothesis that hydrocortisone might be effective in the treatments of CFS. In the first study, $70 \mathrm{pa}-$ tients were randomized to receive either active $\left(13 \mathrm{mg} / \mathrm{m}^{2}\right.$ of body surface area at $8 \mathrm{a} . \mathrm{m}$. and $3 \mathrm{mg} / \mathrm{m}^{2}$ at $2 \mathrm{p} . \mathrm{m}$.) or placebo treatment for 3 months [81]. There was a moderate but significant benefit of hydrocortisone on a global health scale, but not on other more specific measures of fatigue or disability. A second study used much lower doses of hydrocortisone (5-10 mg daily) [82]. Thirty-two subjects entered a placebo-controlled crossover trial, with 28 days on each treatment. There was a clinically significant fall in self-reported fatigue scores in $34 \%$ of the patients on active treatment, compared to $13 \%$ on placebo. However, Blockmans et al. [83] found no differences between treatment with a combination therapy (hydrocor- tisone $5 \mathrm{mg} /$ day and 9 - $\alpha$-fludrocortisone $50 \mu \mathrm{g} / \mathrm{day}$ ) and placebo in a 6-month randomized double-blind crossover study in 100 CFS patients. Taken together, hydrocortisone replacement therapy cannot be recommended for clinical use because of the limited benefit, because of the loss of efficacy upon discontinuation [82] and because of the adrenal suppression when using higher doses [81]. However, the symptomatic improvement in 2 of the 3 trials is concordant with an evolvement of the HPA axis in symptom propagation in CFS.

\section{Conclusion}

In conclusion, the HPA axis remains an intriguing field of research in CFS. Globally, there is evidence for a reduced cortisol output and HPA axis hypofunction in a proportion of patients with CFS, despite the negative studies and methodological difficulties. Mild hypocortisolism, blunted ACTH responses in challenge tests and enhanced negative glucocorticoid feedback are the main findings. Several underlying mechanisms have been proposed, but further research on the central CRF system in CFS is needed. Additional studies in humans are also required to examine how HPA axis disturbances evolve in time and to determine their role in the predisposition for stress-related disorders. It is likely though that the HPA axis is a relevant factor in symptom propagation in CFS, even if the disturbances are secondary to other factors.

\section{Acknowledgments}

This work was supported by the Special Research Fund of the University of Antwerp, the Fund for Scientific Research Flanders (FWO-F) and the Interuniversity Attraction Poles (IUAP) program P5/19 of the Belgian Science Policy Office. S.J. Claes is a senior clinical researcher of the FWO-F.

\section{References}

1 Fukuda K, Straus SE, Hickie I, Sharpe MC, Dobbins JG, Komaroff A: The chronic fatigue syndrome: a comprehensive approach to its definition and study. International Chronic Fatigue Syndrome Study Group. Ann Intern Med 1994;121:953-959.

2 Cleare AJ: The neuroendocrinology of chronic fatigue syndrome. Endocr Rev 2003; 24:236-252.
3 Poteliakhoff A: Adrenocortical activity and some clinical findings in acute and chronic fatigue. J Psychosom Res 1981;25:91-95.

4 Afari N, Buchwald D: Chronic fatigue syndrome: a review. Am J Psychiatry 2003;160: 221-236.

5 Hatcher S, House A: Life events, difficulties and dilemmas in the onset of chronic fatigue syndrome: a case-control study. Psychol Med 2003;33:1185-1192.
6 Heim C, Wagner D, Maloney E, Papanicolaou DA, Solomon L, Jones JF, Unger ER, Reeves WC: Early adverse experience and risk for chronic fatigue syndrome: results from a population-based study. Arch Gen Psychiatry 2006;63:1258-1266.

7 Kato K, Sullivan PF, Evengard B, Pedersen NL: Premorbid predictors of chronic fatigue. Arch Gen Psychiatry 2006;63:1267-1272. 
8 Prins JB, van der Meer JW, Bleijenberg G: Chronic fatigue syndrome. Lancet 2006;367: 346-355.

9 Theorell T, Blomkvist V, Lindh G, Evengard B: Critical life events, infections, and symptoms during the year preceding chronic fatigue syndrome (CFS): an examination of CFS patients and subjects with a nonspecific life crisis. Psychosom Med 2005;61:304-310.

10 Van Houdenhove B, Neerinckx E, Lysens R, Vertommen H, Van Houdenhove L, Onghena P, Westhovens R, D'Hooghe MB: Victimization in chronic fatigue syndrome and $\mathrm{fi}-$ bromyalgia in tertiary care: a controlled study on prevalence and characteristics. Psychosomatics 2001;42:21-28.

11 Van Houdenhove B, Neerinckx E, Onghena P, Lysens R, Vertommen H: Premorbid 'overactive' lifestyle in chronic fatigue syndrome and fibromyalgia. An etiological factor or proof of good citizenship? J Psychosom Res 2001;51:571-576.

12 Fries E, Hesse J, Hellhammer J, Hellhammer DH: A new view on hypocortisolism. Psychoneuroendocrinology 2005;30:1010-1016.

13 Gold PW, Chrousos GP: Organization of the stress system and its dysregulation in melancholic and atypical depression: high vs low CRH/NE states. Mol Psychiatry 2002;7:254275.

14 Heim C, Ehlert U, Hellhammer DH: The potential role of hypocortisolism in the pathophysiology of stress-related bodily disorders. Psychoneuroendocrinology 2000;25:1-35.

15 Parker AJ, Wessely S, Cleare AJ: The neuroendocrinology of chronic fatigue syndrome and fibromyalgia. Psychol Med 2001;31: 1331-1345.

16 Wood B, Wessely S, Papadopoulos A, Poon L, Checkley S: Salivary cortisol profiles in chronic fatigue syndrome. Neuropsychobiology 1998;37:1-4

17 Jerjes WK, Peters TJ, Taylor NF, Wood PJ, Wessely S, Cleare AJ: Diurnal excretion of urinary cortisol, cortisone, and cortisol metabolites in chronic fatigue syndrome. J Psychosom Res 2006;60:145-153.

18 Roberts AD, Wessely S, Chalder T, Papadopoulos A, Cleare AJ: Salivary cortisol response to awakening in chronic fatigue syndrome. Br J Psychiatry 2004;184:136-141.

19 Di Giorgio A, Hudson M, Jerjes W, Cleare AJ 24-hour pituitary and adrenal hormone profiles in chronic fatigue syndrome. Psychosom Med 2005;67:433-440.

20 Demitrack MA, Dale JK, Straus SE, Laue L, Listwak SJ, Kruesi MJ, Chrousos, GP, Gold PW: Evidence for impaired activation of the hypothalamic-pituitary-adrenal axis in patients with chronic fatigue syndrome. J Clin Endocrinol Metab 1991;73:1224-1234.

21 Demitrack MA, Crofford LJ: Evidence for and pathophysiologic implications of hypothalamic-pituitary-adrenal axis dysregulation in fibromyalgia and chronic fatigue syndrome. Ann NY Acad Sci 1998;840:684697.

HPA Axis Function in Chronic Fatigue Syndrome
22 Fish HR, Chernow B, O’Brian JT: Endocrine and neurophysiologic responses of the pituitary to insulin-induced hypoglycemia: a review. Metabolism 1986;35:763-780.

23 Gaab J, Huster D, Peisen R, Engert V, Heitz V, Schad T, Schurmeyer TH, Ehlert U: Hypothalamic-pituitary-adrenal axis reactivity in chronic fatigue syndrome and health under psychological, physiological, and pharmacological stimulation. Psychosom Med 2002; 64:951-962.

24 Cleare AJ, Miell J, Heap E, Sookdeo S, Young L, Malhi GS, O’Keane V: Hypothalamo-pituitary-adrenal axis dysfunction in chronic fatigue syndrome, and the effects of lowdose hydrocortisone therapy. J Clin Endocrinol Metab 2001;86:3545-3554.

25 Moorkens G, Berwaerts J, Wynants H, Abs $\mathrm{R}$ : Characterization of pituitary function with emphasis on $\mathrm{GH}$ secretion in the chronic fatigue syndrome. Clin Endocrinol 2000; 53:99-106.

26 Bearn J, Allain T, Coskeran P, Munro N, Butler J, McGregor A, Wessely S: Neuroendocrine responses to d-fenfluramine and insulin-induced hypoglycemia in chronic fatigue syndrome. Biol Psychiatry 1995;37:245-252.

27 Scott LV, Medbak S, Dinan TG: Blunted adrenocorticotropin and cortisol responses to corticotropin-releasing hormone stimulation in chronic fatigue syndrome. Acta Psychiatr Scand 1998;97:450-457.

28 Inder WJ, Prickett TC, Mulder RT: Normal opioid tone and hypothalamic-pituitary-adrenal axis function in chronic fatigue syndrome despite marked functional impairment. Clin Endocrinol 2005;62:343-348.

29 Altemus M, Dale JK, Michelson D, Demitrack MA, Gold PW, Straus SE: Abnormalities in response to vasopressin infusion in chronic fatigue syndrome. Psychoneuroendocrinology 2001;26:175-188.

30 Scott LV, Medbak S, Dinan TG: Desmopressin augments pituitary-adrenal responsivity to corticotropin-releasing hormone in subjects with chronic fatigue syndrome and in healthy volunteers. Biol Psychiatry 1999;45: 1447-1454.

31 Scott LV, Burnett F, Medbak S, Dinan TG: Naloxone-mediated activation of the hypothalamic-pituitary-adrenal axis in chronic fatigue syndrome. Psychol Med 1998;28: 285-293.

32 Gaab J, Huster D, Peisen R, Engert V, Schad T, Schurmeyer TH, Schurmeyer TH, Ehlert $\mathrm{U}$ : Low-dose dexamethasone suppression test in chronic fatigue syndrome and health. Psychosom Med 2002;64:311-318.

33 Gaab J, Huster D, Peisen R, Engert V, Heitz V, Schad T, Schurmeyer TH, Ehlert U: Assessment of cortisol response with low-dose and high-dose ACTH in patients with chronic fatigue syndrome and healthy comparison subjects. Psychosomatics 2003;44:113-119.
34 Hudson M, Cleare AJ: The 1microg short Synacthen test in chronic fatigue syndrome. Clin Endocrinol 1999;51:625-630.

35 Scott LV, Medbak S, Dinan TG: The low dose ACTH test in chronic fatigue syndrome and in health. Clin Endocrinol 1998;48:733-777.

36 Scott LV, The J, Reznek R, Martin A, Sohaib A, Dinan TG: Small adrenal glands in chronic fatigue syndrome: a preliminary computer tomography study. Psychoneuroendocrinology 1999;24:759-768.

37 Cleare AJ: The HPA axis and the genesis of chronic fatigue syndrome. Trends Endocrinol Metab 2004;15:55-59.

38 Claes SJ: CRH, stress, and major depression: a psychobiological interplay. Vitam Horm 2004;69:117-150

39 Heim C, Plotsky PM, Nemeroff CB: Importance of studying the contributions of early adverse experience to neurobiological findings in depression. Neuropsychopharmacology 2004;29:641-648.

40 Van Houdenhove B, Egle UT: Fibromyalgia: a stress disorder? Piecing the biopsychosocial puzzle together. Psychother Psychosom 2004;73:267-275.

41 Crofford LJ, Pillemer SR, Kalogeras KT, Cash JM, Michelson D, Kling MA, Sternberg EM, Gold PW, Chrousos GP, Wilder RL: Hypothalamic-pituitary-adrenal axis perturbations in patients with fibromyalgia. Arthritis Rheum 1994;37:1583-1592.

42 Griep EN, Boersma JW, de Kloet ER: Altered reactivity of the hypothalamic-pituitary-adrenal axis in the primary fibromyalgia syndrome. J Rheumatol 1993;20:469-474.

43 Griep EN, Boersma JW, Lentjes EG, Prins AP, van der Korst JK, de Kloet ER: Function of the hypothalamic-pituitary-adrenal axis in patients with fibromyalgia and low back pain. J Rheumatol 1998;25:1374-1381.

44 Crofford LJ, Young EA, Engleberg NC, Korszun A, Brucksch CB, McClure LA Brown MB, Demitrack MA: Basal circadian and pulsatile ACTH and cortisol secretion in patients with fibromyalgia and/or chronic fatigue syndrome. Brain Behav Immun 2004; 18:314-325.

45 Gaab J, Engert V, Heitz V, Schad T, Schurmeyer TH, Ehlert U: Associations between neuroendocrine responses to the Insulin Tolerance Test and patient characteristics in chronic fatigue syndrome. J Psychosom Res 2004;56:419-424.

46 Kirschbaum C, Kudielka BM, Gaab J, Schommer NC, Hellhammer DH: Impact of gender, menstrual cycle phase, and oral contraceptives on the activity of the hypothalamus-pituitary-adrenal axis. Psychosom Med 1999; 61:154-162.

47 Gaab J, Rohleder N, Heitz V, Schad T, Engert V, Schürmeyer TH, Ehlert U: Enhanced glucocorticoid sensitivity in patients with chronic fatigue syndrome. Acta Neuropsychiatr 2003;15:184-191. 
48 Visser J, Blauw B, Hinloopen B, Brommer E, de Kloet ER, Kluft C, Nagelkerken L: CD4 T lymphocytes from patients with chronic fatigue syndrome have decreased interferongamma production and increased sensitivity to dexamethasone. J Infect Dis 1998;177: 451-454.

49 Visser J, Graffelman W, Blauw B, Haspels I, Lentjes E, de Kloet ER, Nagelkerken L: LPSinduced IL-10 production in whole blood cultures from chronic fatigue syndrome patients is increased but supersensitive to inhibition by dexamethasone. J Neuroimmunol 2001;119:343-349.

50 Visser J, Lentjes E, Haspels I, Graffelman W, Blauw B, de Kloet R, Nagelkerken L: Increased sensitivity to glucocorticoids in peripheral blood mononuclear cells of chronic fatigue syndrome patients, without evidence for altered density or affinity of glucocorticoid receptors. J Investig Med 2001;49:195-204.

51 Chrousos GP, Gold PW: The concepts of stress and stress system disorders. Overview of physical and behavioral homeostasis. JAMA 1992;267:1244-1252.

52 Heim C, Nemeroff CB: The impact of early adverse experiences on brain systems involved in the pathophysiology of anxiety and affective disorders. Biol Psychiatry 1999;46: 1509-1522.

53 Yehuda R, Southwick SM, Krystal JH, Bremner D, Charney DS, Mason JW: Enhanced suppression of cortisol following dexamethasone administration in posttraumatic stress disorder. Am J Psychiatry 1993;150:83-86.

54 Rinne T, de Kloet ER, Wouters L, Goekoop JG, DeRijk RH, van den Brink W: Hyperresponsiveness of hypothalamic-pituitary-adrenal axis to combined dexamethasone/corticotropin-releasing hormone challenge in female borderline personality disorder subjects with a history of sustained childhood abuse. Biol Psychiatry 2002;52:1102-1112.

55 Newport DJ, Heim C, Bonsall R, Miller AH, Nemeroff CB: Pituitary-adrenal responses to standard and low-dose dexamethasone suppression tests in adult survivors of child abuse. Biol Psychiatry 2004;55:10-20.

56 Stein MB, Yehuda R, Koverola C, Hanna C: Enhanced dexamethasone suppression of plasma cortisol in adult women traumatized by childhood sexual abuse. Biol Psychiatry 1997;42:680-686

57 De Souza EB: Corticotropin-releasing factor receptors: physiology, pharmacology, biochemistry and role in central nervous system and immune disorders. Psychoneuroendocrinology 1995;20:789-819.

58 Brown MR, Fisher LA, Spiess J, Rivier C, Rivier J, Vale W: Corticotropin-releasing factor: actions on the sympathetic nervous system and metabolism. Endocrinology 1982;111: 928-931.

59 Sutton RE, Koob GF, Le Moal M, Rivier J, Vale W: Corticotropin releasing factor produces behavioural activation in rats. Nature 1992;297:331-333.
60 Chang FC, Opp MR: Corticotropin-releasing hormone $(\mathrm{CRH})$ as a regulator of waking. Neurosci Biobehav Rev 2001;25:445-453.

61 Lariviere WR, Melzack R: The role of corticotropin-releasing factor in pain and analgesia. Pain 2000;84:1-12.

62 Steiger A: Neurochemical regulation of sleep. J Psychiatr Res 2007;41:537-552.

63 Reeves WC, Heim C, Maloney EM, Youngblood LS, Unger ER, Decker MJ: Sleep characteristics of persons with chronic fatigue syndrome and non-fatigued controls: results from a population-based study. BMC Neurol 2006;6:41.

64 Gerrity TR, Papanicolaou DA, Amsterdam JD, Bingham S, Grossman A, Hedrick T, Herberman, RB, Krueger G, Levine S, Mohagheghpour N, Moore RC, Oleske J, Snell CR; CFIDS Association of America: Immunologic aspects of chronic fatigue syndrome. Report on a Research Symposium convened by The CFIDS Association of America and co-sponsored by the US Centers for Disease Control and Prevention and the National Institutes of Health. Neuroimmunomodulation 2004;11:351-357.

65 Dantzer R: Somatization: a psychoneuroimmune perspective. Psychoneuroendocrinology 2005;30:947-952.

66 Chalder T, Godfrey E, Ridsdale L, King M, Wessely S: Predictors of outcome in a fatigued population in primary care following a randomized controlled trial. Psychol Med 2003;33:283-287.

67 Rubin GJ, Hotopf M, Papadopoulos A, Cleare AJ: Salivary cortisol as a predictor of postoperative fatigue. Psychosom Med 2005;67: 441-447.

68 Glass JM, Lyden AK, Petzke F, Stein P, Whalen G, Ambrose K, Chrousos G, Clauw DJ: The effect of brief exercise cessation on pain, fatigue, and mood symptom development in healthy, fit individuals. J Psychosom Res 2004;57:391-398.

69 Van Houdenhove B: Premorbid 'overactive' lifestyle and stress-related pain/fatigue syndromes. J Psychosom Res 2005;58:389-390.

70 McEwen BS: Mood disorders and allostatic load. Biol Psychiatry 2003;54:200-207.

71 Houshyar H, Galigniana MD, Pratt WB, Woods JH: Differential responsivity of the hypothalamic-pituitary-adrenal axis to glucocorticoid negative-feedback and corticotropin releasing hormone in rats undergoing morphine withdrawal: possible mechanisms involved in facilitated and attenuated stress responses. J Neuroendocrinol 2001;13:875886.

72 Claes SJ, Villafuerte S, Forsgren T, Sluijs S, Del-Favero J, Adolfsson R, Van Broeckhoven C: The corticotropin-releasing hormone binding protein is associated with major depression in a population from Northern Sweden. Biol Psychiatry 2003;54:867-872.
73 van Rossum EF, Binder EB, Majer M, Koper JW, Ising M, Modell S, Salyakina D, Lamberts SW, Holsboer F: Polymorphisms of the glucocorticoid receptor gene and major depression. Biol Psychiatry 2006;59:681-688.

74 van West D, Del-Favero J, Aulchenko Y, Oswald P, Souery D, Forsgren T, Sluijs S, Bel Kacem S, Adolfsson R, Mendlewicz J, Van Duijn C, Deboutte D, Van Broeckhoven C, Claes SJ: A major SNP haplotype of the arginine vasopressin $1 \mathrm{~B}$ receptor protects against recurrent major depression. Mol Psychiatry 2004;9:287-292.

75 van West D, Van Den Eede F, Del-Favero J, Souery D, Norrback KF, Van Duijn C, Sluijs S, Adolfsson R, Mendlewicz J, Deboutte D, Van Broeckhoven C, Claes SJ: Glucocorticoid receptor gene-based SNP analysis in patients with recurrent major depression. Neuropsychopharmacology 2006;31:620-627.

76 Goertzel BN, Pennachin C, de Souza Coelho L, Gurbaxani B, Maloney EM, Jones JF: Combinations of single nucleotide polymorphisms in neuroendocrine effector and receptor genes predict chronic fatigue syndrome. Pharmacogenomics 2006;7:475483.

77 Kaiser J: Biomedicine. Genes and chronic fatigue: how strong is the evidence? Science 2006;312:669-671.

78 Rajeevan MS, Smith AK, Dimulescu I, Unger ER, Vernon SD, Heim C, Reeves WC: Glucocorticoid receptor polymorphisms and haplotypes associated with chronic fatigue syndrome. Genes Brain Behav 2007;6:167-176.

79 Halbreich U: Major depression is not a diagnosis, it is a departure point to differential diagnosis - clinical and hormonal considerations (a commentary and elaboration on Antonejevic's paper). Psychoneuroendocrinology 2006;31:16-22.

80 Baschetti R: Chronic fatigue syndrome: a form of Addison's disease. J Intern Med 2000;247:737-739.

81 McKenzie R, O’Fallon A, Dale J, Demitrack M, Sharma G, Deloria M, Garcia-Borreguero D, Blackwelder W, Straus SE: Low-dose hydrocortisone for treatment of chronic fatigue syndrome: a randomized controlled trial. JAMA 1998;280:1061-1066.

82 Cleare AJ, Heap E, Malhi GS, Wessely S, O'Keane V, Miell J: Low-dose hydrocortisone in chronic fatigue syndrome: a randomised crossover trial. Lancet 1999;353: 455-458.

83 Blockmans D, Persoons P, Van Houdenhove $\mathrm{B}$, Lejeune $\mathrm{M}$, Bobbaers $\mathrm{H}$ : Combination therapy with hydrocortisone and fludrocortisone does not improve symptoms in chronic fatigue syndrome: a randomized, placebocontrolled, double-blind, crossover study. Am J Med 2003;114:736-741.
Van Den Eede/Moorkens/ Van Houdenhove/Cosyns/Claes 